\title{
The Effect of Tree Cover and Vegetation on Incidence of Childhood Asthma in Metropolitan Statistical Areas of Texas
}

\author{
Monica Ann Pilat ${ }^{1}$, Amy McFarland ${ }^{2}$, Amy Snelgrove ${ }^{3}$, \\ Kevin Collins ${ }^{4}$, Tina Marie Waliczek ${ }^{5,7}$, and Jayne Zajicek ${ }^{6}$
}

ADDITIONAL INDEX WORDs. urban forest, canopy cover, $\mathrm{ArcView}^{\mathrm{TM}}$, normalized difference vegetation index

SUMMARY. The number of asthma cases in children has increased significantly in the last couple of decades. Studies on links between outdoor air pollutants and asthma have had mixed results, suggesting the need for more focused studies. An increase in tree plantings for urban areas is now being called upon as a solution to the higher heat indexes and pollution rates for more densely populated areas. Green spaces and trees could further benefit some urban areas by providing an effective means to improve air conditions. The purpose of this study was to assess whether there is a relationship between levels of vegetation and reported rates of childhood asthma in Texas. Childhood asthma data were collected from the Center for Health Statistics and the Texas Department of State Health Services for the years 2005 and 2006. The asthma rates for each metropolitan statistical area (MSA) were mapped and inserted into a corresponding vegetation map using geographical mapping software. A comparison of vegetation rates and asthma rates in metropolitan areas was used to investigate whether vegetation and tree cover led to higher or lower incidences of childhood asthma rates. Asthma data, normalized difference vegetation index (NDVI), and canopy cover data were analyzed using statistical software. Regression analysis and correlations were calculated to analyze the data for the tree coverage/vegetation rates and asthma rates variable. No statistically significant relationships between NDVI, canopy cover, and asthma were found in this study.

A sthma has been defined as a common and chronic inflammatory condition of the airways in which a narrowing of the mediumsized air passages of the lungs causes wheezing, shortness of breath, and coughing (Elsom, 1996; Williams, 2005). The cause of asthma is not completely known, and a combination of host and environmental factors appear to be involved with the development and trigger factors of asthma (Thurston and Ito, 1999; Tunnicliffe and Ayres, 2001). Environmental elements such as tobacco smoke, pet dander, american house dust mites

${ }^{1}$ Graduate Assistant, Department of Agriculture, Texas State University-San Marcos, San Marcos, TX 78666

${ }^{2}$ Haupt Fellow, Smithsonian Gardens, Smithsonian Institution, Washington, DC 20013

${ }^{3}$ GIS Specialist, Texas A\&M Institute of Renewable Natural Resources, College Station, TX 77843

${ }^{4}$ Assistant Professor, Department of Respiratory Care, Texas State University-San Marcos, San Marcos, TX 78666

${ }^{5}$ Professor, Department of Agriculture, Texas State University-San Marcos, San Marcos, TX 78666

${ }^{6}$ Professor, Department of Horticultural Sciences, Texas A\&M University, College Station, TX 77845

${ }^{7}$ Corresponding author. E-mail: tcl0@txstate.edu.
(Dermatophagoides farinae), and american cockroaches (Periplaneta americana) contribute to asthma irritation and asthma severity in the indoor environment (Edelman, 1997; Lara et al., 2001). Outdoor air pollution is also known to trigger asthma symptoms in both children and adults (Walling, 2002; Woodruff et al., 2003).

Childhood asthma is the most common chronic disease in children, with increases in the number of cases occurring in industrialized countries (Bellenir, 2006; O'Connell, 2004; Walling, 2002). Asthma affects $\approx 20$ million people in the United States, and children make up more than onethird of those affected (Sommers et al., 2007). In 2000, the American Academy of Pediatrics reported that asthma rates for those less than 18 years old had increased by more than $70 \%$ from 1982 to 1994 (Neidell, 2004). It was also reported that the percentage of children with asthma doubled from $3.6 \%$ in 1980 to $7.5 \%$ in 1995 , and a survey administered in 2001 indicated that 6.3 million or $8.7 \%$ of children had asthma (Akinbami, 2006; Woodruffet al., 2003). The total cost for asthma in 1994 was $\approx \$ 5.8$ billion (Smith et al., 1997). O'Connell (2004) estimated this annual cost increased to $\$ 14$ billion in 2004 .

Numerous time-series studies of hospital admissions and emergency visits have suggested a connection between particulate air pollution and asthma attacks (Dockery and Pope, 1996). Pollutants including sulfur dioxide, ozone, acid aerosols, fine particulates, and nitrogen dioxide are all believed to sensitize people to asthma (Elsom, 1996). Studies of children with asthma at summer camps found that air pollution, particularly ozone, was significantly and consistently correlated with acute asthma exacerbations, chest symptoms, and lung function decrements (Thurston and Ito, 1999). Inflammation of allergic asthmatics has been shown to increase with air pollutants such as ozone and that repeated exposure to ozone would likely have a detrimental effect on lung function of asthmatics (Devlin et al., 1996). Finally, research has suggested that long-term exposure to urban air pollution is related to prevalence of asthma and allergies, primarily those pollutants emitted by traffic in urban areas (Pénard-Morand et al., 2010).

Trees remove airborne dust and chemical matter, or particulate matter from the air, where it is stored on leaves, twigs, and trunks (Beckett et al., 1998). Particulary, leaf magnetization studies have found high values from leaves on the side of a tree closer to the roadside and lower values at the distal side, confirming the ability of trees to reduce aerosol concentrations related to vehicular pollutants in the atmosphere (Matzka and Maher, 1999). Tree cover or "green belts" around factories and other industrial locations reduce air pollution by serving as a sink for pollutants and reducing the flow of dust (Rao et al., 2004). Rao et al. (2004) found that planting around

\begin{tabular}{llll}
\hline $\begin{array}{l}\text { Units } \\
\begin{array}{l}\text { To convert U.S. to SI, } \\
\text { multiply by }\end{array}\end{array}$ & U.S. unit & SI unit & $\begin{array}{l}\text { To convert SI to U.S., } \\
\text { multiply by }\end{array}$ \\
\hline $\mathrm{l}$ & $\begin{array}{l}\text { micron } \\
\operatorname{ton}(\mathrm{s})\end{array}$ & $\mu \mathrm{m}$ & $\mathrm{Mg}$ \\
0.9072 & & 1.1023
\end{tabular}


the industrial area reduced air pollutant emissions by as much as $63 \%$, including a reduction of sulfur dioxide by $39 \%$, nitrogen oxides by $40 \%$, $37 \%$ of particulate matter, and a $93 \%$ reduction in carbon monoxide levels. In 1984 , it was estimated in urban areas that planting 1 million new trees would remove 200 tons of particulate pollution each day after the trees reached 10 years of age (Petit et al., 1998). Research has also suggested that using grasses and shrubs on rooftops could help reduce air pollution in urban areas by increasing the amount of vegetation in areas with limited space (Currie and Bass, 2008). Furthermore, research has suggested that an increase in tree density is related to a decrease in the prevalence of asthma in urban areas such as New York City (Lovasi et al., 2008).

Texas has a wide variety of climate and geography conditions across the state, which leads to a diversity in native vegetation classified as forests, woodlands, shrublands, grasslands, herbaceous vegetation, swamps, and marshes (Diamond et al., 1987). The main objective for this study was to determine if childhood asthma rates were related to tree cover and vegetation in the MSAs of Texas.

\section{Materials and methods}

MSAs of Texas. The state of Texas has been divided into 25 different MSAs for the purposes of demographic and statistical analyses by various departments and organizations. Each MSA is comprised of a county or group of counties with a population of at least 75,000 and contains a central city or urbanized area of at least 50,000 (Labor Market and Career Information Department of the Texas Workforce Comission, 2006). MSAs include the following regions: Abilene, Amarillo, Austin-Round Rock, Beaumont-Port Arthur, Brownsville-Harlingen, College Station-Bryan, Corpus Christi, Dallas-Fort Worth-Arlington, El Paso, Houston-Sugarland-Baytown, KilleenTemple-Fort Hood, Laredo, Longview, Lubbock, McAllen-Edinburg-Mission, Midland, Odessa, San Angelo, San Antonio, Sherman-Denison, Texarkana, Tyler, Victoria, Waco, and Wichita Falls.

Childhood asthma data. Childhood asthma data were collected from the Center for Health Statistics, Texas Department State Health
Services for the years 2005 and 2006 . Childhood asthma data were available for all counties in Texas with reported populations of 50 or more children living within the county (A. Vincent, personal communication) according to a Research Specialist at the Center for Health Statistics, Texas Department State Health Services. To determine the population for each sample, adult respondents had to provide a valid response of "yes" or "no" to the two questions on a survey concerning a select child under the age of 17 years in their household. The questions asked were as follows: "Has a physician/medical care provider ever told you that this child has asthma?" and "Does this child still have asthma?" Adults who answered "yes" to the two questions concerning a select child under the age of 17 years in their household were considered the asthma sample. To normalize the sample to the general population, the asthma sample was weighted in calculating the percentage of children with asthma (M.L. Cook, personal communication) according to a Research Specialist at the Center for Health Statistics, Texas Department State Health Services.

Asthma data were mapped into the MSAs of Texas to understand the areas of correspondence (E. Pimpler, personal communication) according to Geographic Information System (GIS) specialist at Geospatial Training Services. Of the 25 MSAs, data on childhood asthma rates corresponded with the following 14 regions: Amarillo, Austin-Round Rock, Beaumont-Port Arthur, Brownsville-Harlingen, Corpus Christi, Dallas-Fort Worth-Arlington, El Paso, Houston-Sugarland-Baytown, Killeen-Temple-Fort Hood, Longview, Lubbock, McAllen-Edinburg-Mission, San Antonio, and Tyler. Therefore, these 14 MSAs were included in the study. The remaining 11 MSAs were removed from the study because they included counties with a sample size of less than 50 children living within the county; therefore, data were not available from the reporting agency (A. Vincent, personal communication).

Mapping Vegetative COVer. Landsat $5^{\mathrm{TM}}$ [U.S. Geological Survey (USGS), Sioux Falls, SD] satellite imagery was obtained from USGS Glovis website (U.S. Department of the Interior, 2010). Image "tiles" were downloaded to cover the extent of all MSAs included in the study. Each "tile" covered an area $185 \mathrm{~km}$ wide. To obtain an accurate picture for each MSA, the imagery must be high quality and as cloud free as possible. The images selected and used in the study were designated by USGS as having a cloud cover of $0 \%$ and an image quality of 9 out of 10 although $0 \%$ cloud cover may still include isolated clouds. The downloaded image tiles were for the months of April to July 2006 when possible. This timeframe ensured that vegetation would be present after winter dormancy conditions, and yet still be before summer heat and drought conditions that could affect greenness levels. The year 2006 was chosen to coincide with the collected asthma data. If data with the above criteria were not available, image tiles from the next closest date that was not during dormant months were acquired. Out of the 14 MSAs used in this study, the following three had image tiles from either September or October of 2006 instead of April to July 2006: Dallas-Fort WorthArlington, Lubbock, and KilleenTemple-Fort Hood.

The tiles were then "mosaiced" or pieced together to create one seamless image for each MSA using ArcView@ (version 9.1 GIS; Esri, Redlands, CA) software. "Mosaicing" merges adjacent tiles into one image file removing overlapping values between tiles. To determine the percentage vegetation and greenness for each MSA in the study, the NDVI was calculated from the satellite imagery. This index is a numerical indicator used to analyze remote sensing measurements to determine the amount of green vegetation in the target region. The NDVI was calculated for each image using ENVI $^{\mathrm{TM}}$ (Esri) image processing software. This process resulted in a grid with values ranging from -1 to 1 (barren/non-vegetation to dense green vegetation, respectively).

The NDVI grid was transferred to the GIS software, where statistics were calculated for each MSA. Statistics included the minimum NDVI value, the maximum NDVI value, and mean NDVI value. Percent canopy cover was calculated for each MSA to determine what proportion of each MSA was groundcover vs. woody vegetation such as trees and shrubs. 
Table 1. Minimum, maximum, and average normalized difference vegetation index (NDVI) for metropolitan statistical areas (MSA), ranked in order highest to lowest average NDVI in the study of the effect of tree cover and vegetation on incidence of childhood asthma in MSAs of Texas.

\begin{tabular}{|c|c|c|c|c|}
\hline Ranking & Texas MSA & Minimum $\mathrm{NDVI}^{\mathrm{z}}$ & Maximum NDVI & Avg NDVI \\
\hline 1-highest & Longview & -0.488372 & 0.780488 & 0.530203 \\
\hline 2 & Tyler & -0.485149 & 0.786802 & 0.512377 \\
\hline 3 & Beaumont-Port Arthur & -0.654321 & 0.954023 & 0.447722 \\
\hline 4 & Houston-Sugarland-Baytown & -0.661972 & 0.824176 & 0.435199 \\
\hline 5 & Austin-Round Rock & -0.542857 & 0.719457 & 0.297422 \\
\hline 6 & Dallas-Fort Worth-Arlington & -0.987730 & 0.815385 & 0.255332 \\
\hline 9 & McAllen-Edinburg-Mission & -0.979798 & 0.769231 & 0.214654 \\
\hline 10 & Killeen-Temple-Fort Hood & -0.655172 & 0.740113 & 0.192114 \\
\hline 11 & Corpus Christi & -0.720930 & 0.752294 & 0.189288 \\
\hline 12 & Brownsville-Harlingen & -0.489362 & 0.729167 & 0.156736 \\
\hline 13 & Amarillo & -0.533333 & 0.790476 & 0.109435 \\
\hline 14-lowest & El Paso & -0.555556 & 0.758140 & 0.018904 \\
\hline
\end{tabular}

${ }^{\mathrm{z}}$ Calculated from satellite imagery for each MSA. This index is a simple numerical indicator used to analyze remote sensing measurements to determine the amount of green vegetation in the observed target. The resulting index range for this calculation is -1 to 1 (barren/non-vegetation to dense green vegetation, respectively).

Table 2. Demographic breakdown, including overall population and percent ethnicity, and childhood asthma rate for each metropolitan statistical area (MSA) included in the study of the effect of tree cover and vegetation on incidence of childhood asthma in MSAs of Texas.

\begin{tabular}{|c|c|c|c|c|c|c|}
\hline Texas MSA & Population & $\begin{array}{c}\text { Caucasian } \\
(\%)\end{array}$ & African-American (\%) & Asian (\%) & Hispanic $(\%)^{\mathrm{z}}$ & $\begin{array}{c}\text { Childhood asthma } \\
\text { rate }(\%)\end{array}$ \\
\hline El Paso & 734,669 & 73.9 & 3.1 & 1.0 & 78.2 & 6.3 \\
\hline Amarillo & 242,240 & 79.1 & 5.9 & 1.8 & 19.6 & 15 \\
\hline Lubbock & 267,211 & 74.3 & 7.7 & 1.3 & 27.5 & 5.7 \\
\hline Dallas-Fort Worth-Arlington & $6,145,037$ & 70.8 & 18.2 & 3.6 & 20.6 & 9.0 \\
\hline Tyler & 198,705 & 72.6 & 19.1 & 0.7 & 11.2 & 4.6 \\
\hline Austin-Round Rock & $1,598,161$ & 72.5 & 8.0 & 3.5 & 26.2 & 6.8 \\
\hline San Antonio & $1,990,675$ & 70.6 & 6.6 & 1.5 & 51.2 & 9.8 \\
\hline Houston-Sugarland- Baytown & $5,628,101$ & 69.5 & 14.1 & 3.1 & 24.6 & 8.5 \\
\hline Beaumont-Port Arthur & 376,241 & 68.2 & 24.8 & 2.1 & 8.0 & 7.1 \\
\hline Corpus Christi & 414,376 & 72.9 & 4.0 & 1.1 & 54.7 & 8.5 \\
\hline McAllen-Edinburg-Mission & 710,514 & 77.7 & 0.5 & 0.6 & 88.3 & 3.7 \\
\hline
\end{tabular}

${ }^{2}$ Includes any race.

Table 3. Linear regression analysis calculating the extent to which relative humidity, temperature, ozone, particulate matter, and ethnicity covaried with asthma in the study of the effect of tree cover and vegetation on incidence of childhood asthma in metropolitan statistical areas of Texas.

\begin{tabular}{|c|c|c|c|c|c|}
\hline \multirow[b]{2}{*}{ Model } & \multicolumn{2}{|c|}{ Unstandardized coefficients } & \multirow{2}{*}{$\frac{\text { Standardized coefficients }}{\boldsymbol{\beta}}$} & \multirow[b]{2}{*}{$t$} & \multirow[b]{2}{*}{$P$} \\
\hline & $B$ & SE & & & \\
\hline Constant & 87.097 & 15.625 & & 5.574 & 0.031 * \\
\hline Temperature & -0.016 & 0.046 & -0.082 & -0.338 & 0.768 \\
\hline Ozone & -0.144 & 0.044 & -1.001 & -3.270 & 0.082 \\
\hline Particulate matter & -0.516 & 0.172 & -0.411 & -3.008 & 0.095 \\
\hline Caucasian & -0.711 & 0.128 & -1.152 & -5.539 & 0.031 * \\
\hline Hispanic & -0.127 & 0.029 & -1.830 & -4.453 & $0.047^{*}$ \\
\hline
\end{tabular}

${ }^{2}$ These variables were selected to control for on the basis of a literature review indicated the impact of each of these on asthma rates.

${ }^{*}$ Statistically significant at the 0.05 level. 
Statistics were also calculated for the MSAs using the Multi-Resolution Land Characteristics National Land Cover Data canopy cover dataset (U.S. Department of the Interior, 2012). This data were used in conjunction with the NDVI results for MSA to conduct statistical analyses.

External variables. Data were collected on several external environmental variables which were known to precipitate symptoms of asthma to control for the impact in this study. Relative humidity, temperature, ozone, and particulate matter data were obtained from the Texas Commission on Environmental Quality (TCEQ) for the months that corresponded to those in which NDVI and percent canopy cover were collected (TCEQ, 2012). Temperate climates and a relative humidity level above $60 \%$ contribute to the growth of house dust mites and their allergens [National Asthma Education and Prevention Program (NAEPP), 2007]. Increased pollution levels of ozone and particulate matter less than or equal to $10 \mu \mathrm{m}$ have been reported to precipitate symptoms of asthma (NAEPP, 2007). Data on ethnic breakdown within each MSA was also collected because there is a known relationship between ethnicity and asthma rates (Akinbami, 2006).

Data analysis. Asthma data, NDVI, and canopy cover data were analyzed using SPSS (version 17.0 ${ }^{\mathrm{TM}}$; IBM Corp., Armonk, NY). Descriptive statistics analyzed the vegetation cover of each MSA. A linear regression analysis was used to calculate the extent to which relative humidity, temperature, ozone, particulate matter, and ethnicity covaried with asthma. Semipartial correlations were calculated to analyze the relationship between tree coverage/vegetation rate and asthma rate variables while controlling for the effects of relative humidity, temperature, ozone, particulate matter, and ethnicity on asthma. Because of the missing data among the external variables, only 11 MSAs were used in data analyses.

\section{Results}

Calculating vegetation COVER. The NDVI grid was transferred to $\mathrm{ENVI}^{\mathrm{TM}}$ image processing software, where statistics were calculated for each MSA. NDVI was calculated from satellite imagery (Landsat) for each MSA. Descriptive statistics

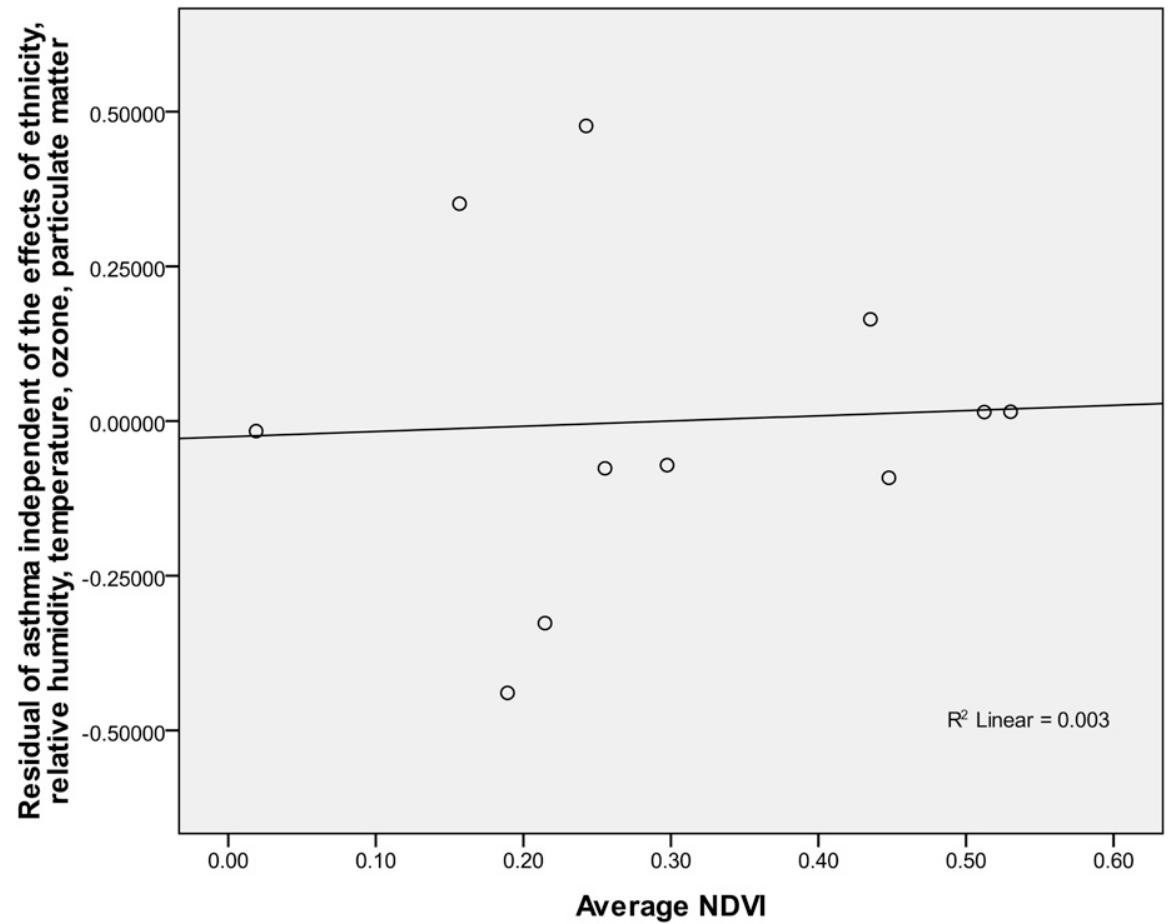

Fig. 1. Scatter-plot diagram indicating the relationship between average normalized difference vegetation index (NDVI) [calculated from satellite imagery for each metropolitan statistical area (MSA)] and the residual of asthma, which controlled for the effect of ethnicity, relative humidity, temperature, ozone, and particulate matter on asthma in the study of the effect of tree cover and vegetation on incidence of childhood asthma in MSAs of Texas. An unstandardized residual of asthma variable was calculated which indicated the asthma rates for each MSA controlling for the extent to which relative humidity, temperature, ozone, particulate matter, and ethnicity covaried with asthma in this study. NDVI is a simple numerical indicator used to analyze remote sensing measurements to determine the amount of green vegetation in the observed target. The resulting index range for this calculation is -1 to 1 (barren/non-vegetation to dense green vegetation, respectively).

Table 4. Semipartial correlation between average and residual normalized difference vegetation index (NDVI) and asthma independent of the effects of ethnicity, relative humidity, temperature, ozone and particulate matter in the study of the effect of tree cover and vegetation on incidence of childhood asthma in metropolitan statistical areas (MSA) of Texas.

\begin{tabular}{llc}
\hline & & Asthma residual $^{\mathbf{z}}$ \\
\hline & Correlation & 0.052 \\
Average NDVI & $P$ & 0.880 \\
& $N$ & 11 \\
Residual NDVI $^{\mathrm{x}}$ & Correlation & -0.328 \\
& $P$ & 0.325 \\
& $N$ & 11 \\
\hline
\end{tabular}

${ }^{2}$ Calculated using a linear regression analysis which indicated the asthma rates for each MSA controlling for the extent to which relative humidity, temperature, ozone, particulate matter, and ethnicity covaried with asthma in this study.

${ }^{y}$ Calculated from satellite imagery for each MSA. This index is a simple numerical indicator used to analyze remote sensing measurements to determine the amount of green vegetation in the observed target. The resulting index range for this calculation is $-\mathrm{l}$ to $\mathrm{l}$ (barren/non-vegetation to dense green vegetation, respectively).

${ }^{\mathrm{x}}$ Calculated using a linear regression analysis which indicated the vegetation rates for each MSA controlling for canopy cover to evaluate the relationship between shrubs and other vegetation and asthma rates.

determined minimum NDVI value, maximum NDVI value, and the average NDVI value for each MSA within the study (Table 1). The MSAs were listed in order from highest to lowest average NDVI value.

Demographic BREAKDOWN. The demographic breakdown including 
overall population and percent ethnicity, and childhood asthma rate for each MSA included in the study on the effects of tree cover and vegetation on childhood asthma rates in regions of Texas was collected to control for the effects of demographic differences in each MSA (Table 2).

Controlling FOR EXTERnAL VARIABLES. A linear regression analysis was used to calculate the extent to which relative humidity, temperature, ozone, particulate matter, and ethnicity covaried with asthma (Table 3 ). An unstandardized residual of asthma variable was calculated which indicated the asthma rates for each MSA controlling for the extent to which relative humidity, temperature, ozone, particulate matter, and ethnicity covaried with asthma in this study. This calculated value is used later in the study to independently assess asthma's relationship with the variables of interest while controlling for the external variables identified. Specific variables which were significantly related to asthma rates included the percentage of Caucasian $(P=0.031)$ and Hispanic $(P=0.047)$ people living within each MSA.

NDVI AND Asthma. A Pearson's product-moment correlation between the average NDVI and the residual asthma variable was calculated. This resulted in a semipartial correlation investigating the relationship between average NDVI and asthma controlling for the effects of external variables on asthma. No statistically significant relationship was found (Fig. 1; Table 4). This finding indicated that, in this study, there was no relationship between overall vegetation calculated by the NDVI and asthma independent of the external variables identified previously.

To investigate the relationship between the quantity of shrubs and other vegetation independent of canopy cover and asthma, a linear regression analysis was used to calculate the extent to which percent canopy cover covaried with average NDVI (Table 5 ). An unstandardized residual of NDVI variable was calculated which indicated the NDVI controlling for canopy cover. This variable was then used in a Pearson's product-moment correlation with the residual asthma variable to indicate the extent to which shrubs and other vegetation independent of tree cover and asthma rates independent of relative humidity, temperature, ozone, particulate matter, and ethnicity were related. No statistically significant relationship was found (Fig. 2; Table 4). This indicated that, in this study, no relationship between vegetation independent of canopy cover and asthma was identified. Given that both woody and herbaceous vegetation have the ability to

Table 5. Linear regression analysis calculating the extent to which canopy cover covaried with average normalized difference vegetation index in the study of the effect of tree cover and vegetation on incidence of childhood asthma in metropolitan statistical areas of Texas.

\begin{tabular}{|c|c|c|c|c|c|}
\hline \multirow[b]{2}{*}{ Model } & \multicolumn{2}{|c|}{ Unstandardized coefficients } & \multirow{2}{*}{$\frac{\text { Standardized coefficients }}{\beta}$} & \multirow[b]{2}{*}{$t$} & \multirow[b]{2}{*}{$P$} \\
\hline & $B$ & SE & & & \\
\hline Constant & 0.124 & 0.026 & & 4.687 & 0.001 * \\
\hline $\begin{array}{l}\text { Canopy } \\
\text { cover }(\%)\end{array}$ & 0.009 & 0.001 & 0.910 & 7.624 & 0.001 * \\
\hline
\end{tabular}

*Statistically significant at the 0.05 level.

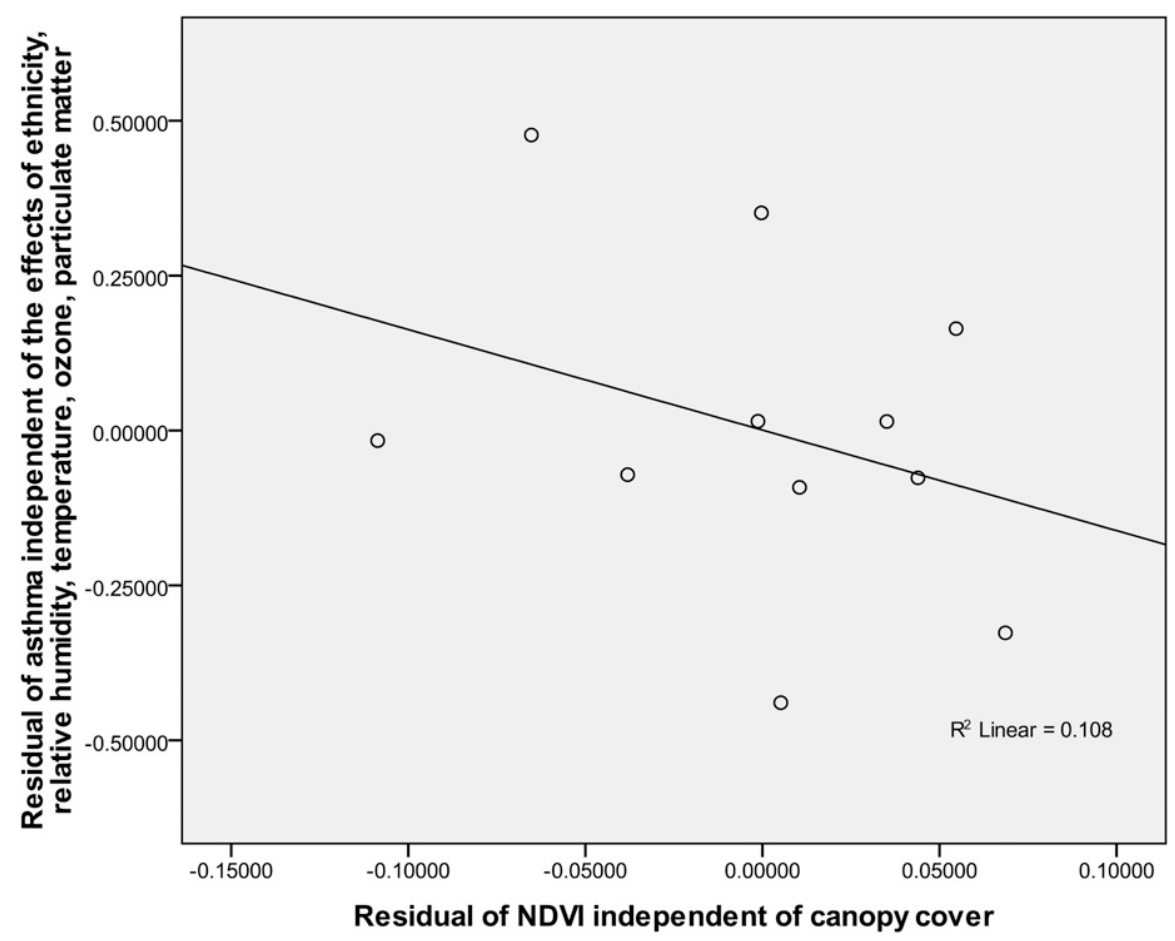

Fig. 2. Scatter-plot diagram indicating the relationship between residual normalized difference vegetation index (NDVI) [calculated from satellite imagery for each metropolitan statistical area (MSA)], which controlled for the effect of canopy cover on NDVI, and the residual of asthma, which controlled for the effect of ethnicity, relative humidity, temperature, ozone and particulate matter on asthma in the study of the effect of tree cover and vegetation on incidence of childhood asthma in MSAs of Texas. An unstandardized residual of asthma variable was calculated which indicated the asthma rates for each MSA controlling for the extent to which relative humidity, temperature, ozone, particulate matter, and ethnicity covaried with asthma in this study. An unstandardized residual of NDVI variable was calculated which indicated the NDVI controlling for canopy cover. NDVI is a simple numerical indicator used to analyze remote sensing measurements to determine the amount of green vegetation in the observed target. The resulting index range for this calculation is -1 to 1 (barren/non-vegetation to dense green vegetation, respectively). 
Canopy cover and asthma. A Pearson's product-moment correlation between the percent canopy cover and the residual asthma variable was calculated. This resulted in a semipartial correlation investigating the relationship between percent canopy cover and asthma controlling for the effects of external variables on asthma. No statistically significant relationship was found (Fig. 3; Table 6). This suggested that there was no relationship between percent canopy cover and the prevalence of asthma in children when controlling for the external variables previously identified in this study.

\section{Discussion}

This study did not find that childhood asthma rates in MSAs of Texas were related to tree cover or vegetation. Childhood asthma occurrence has many extraneous variables such as tobacco smoke, pet dander, dust mites, and cockroaches related to the disease which may have influenced the research and results (Edelman, 1997; Lara et al., 2001). Tree pollen from species such as ash (Fraximus sp.), elm (Ulmus sp.), oak (Quercus sp.), and sycamore (Platanus sp.), as well as, grass pollen are also linked to seasonal asthma in certain patients and these pollen are generally higher in the spring and summer months, the same time frame of this study (MacNaughton, 2007).

One possibility for our findings was the small sample sizes used in this study. It may be prudent to repeat the study including MSAs in other states. Increasing the sample size would increase the power of the study, improving the ability to detect a relationship. Wilson VanVoorhis and Morgan (2007) recommend no less than 50 cases are required for sufficient statistical power in correlational or regression research. Because of the particular constraints in this study, that large of a sample was not able to be obtained; however future research including additional MSAs in other states is in progress.

Another possibility is that the results are affected by the large variation of vegetation in each MSA. As seen in the statistics calculated for each MSA (Table 1), a large range between the minimum NDVI and maximum NDVI exists within each MSA for a single time period. This might indicate that MSAs are too large and too

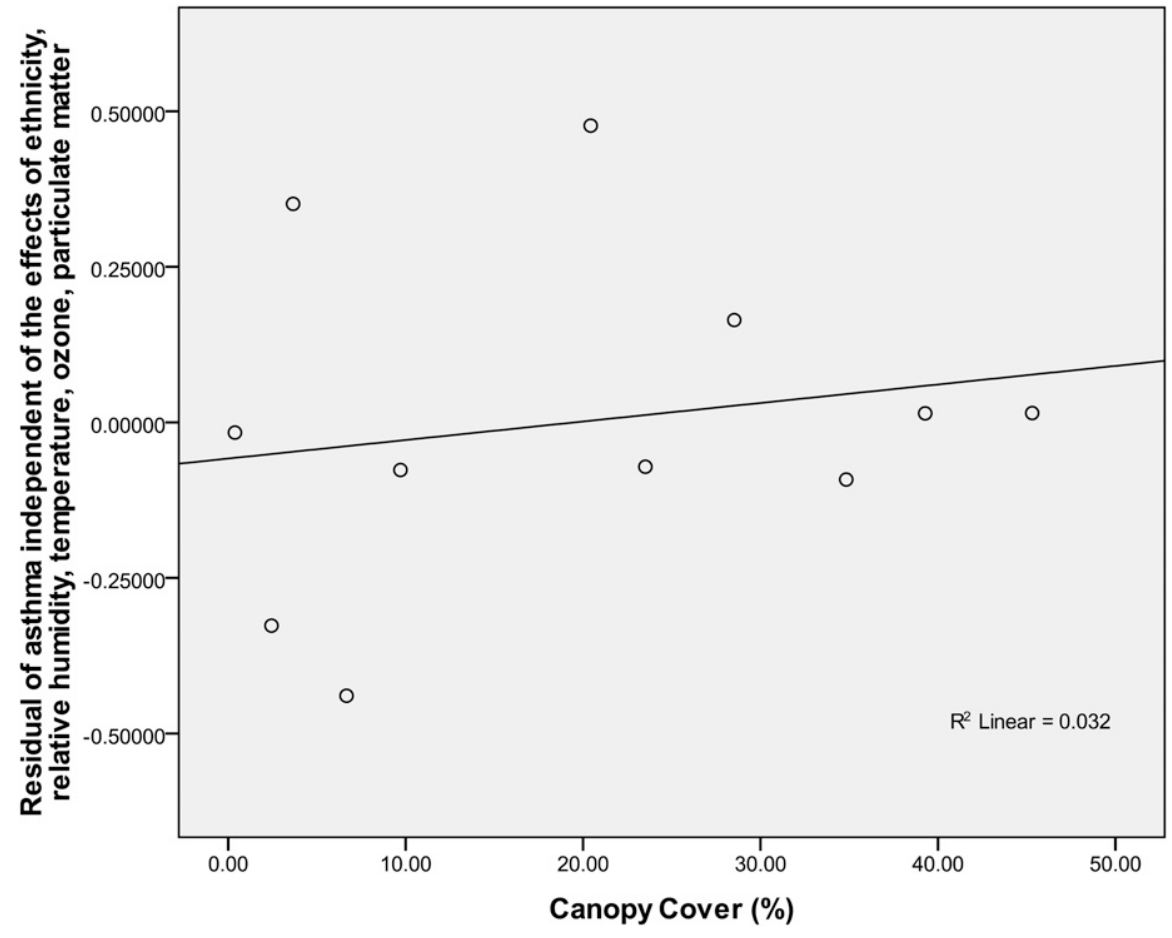

Fig. 3. Scatter-plot diagram indicating the relationship between percent canopy cover and the residual of asthma, which controlled for the effect of ethnicity, relative humidity, temperature, ozone and particulate matter on asthma in the study of the effect of tree cover and vegetation on incidence of childhood asthma in metropolitan statistical areas (MSAs) of Texas. An unstandardized residual of asthma variable was calculated which indicated the asthma rates for each MSA controlling for the extent to which relative humidity, temperature, ozone, particulate matter, and ethnicity covaried with asthma in this study.

Table 6. Semipartial correlation between percent canopy and asthma independent of the effects of ethnicity, relative humidity, temperature, ozone, and particulate matter in the study of the effect of tree cover and vegetation on incidence of childhood asthma in metropolitan statistical areas (MSAs) of Texas.

\begin{tabular}{llc}
\hline & & Asthma residual $^{\mathbf{z}}$ \\
\hline Percent canopy cover & Correlation & 0.180 \\
& $P$ & 0.596 \\
& $N$ & 11 \\
\hline
\end{tabular}

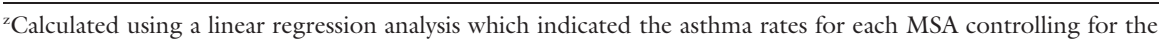
extent to which relative humidity, temperature, ozone, particulate matter, and ethnicity covaried with asthma in this study.

*Statistically significant at the 0.05 level.

varied for this kind of research. Obtaining data at a community level may be difficult but may yield significant results, and is recommended for future research. Additional factors which may be considered in future research include the influence of vehicular pollution, wind, altitude, precipitation, and other demographics related to human stress which may relate to asthma.

\section{Literature cited}

Akbari, H. 2002. Shade trees reduce building energy use and $\mathrm{CO}_{2}$ emissions from power plants. Environ. Pollut. 116:S119S126.

Akinbami, L. 2006. The state of childhood asthma, United States, 1980-2005. Advance data from vital and health statistics 381. U.S. Dept. Health Human Serv., Centers Dis. Control Prevention, Hyattsville, $\mathrm{MD}$.

Beckett, K.P., P.H. Freer-Smith, and G. Taylor. 1998. Urban woodlands: Their role in reducing the effects of particulate pollution. Environ. Pollut. 99:347360 .

Bellenir, K. 2006. Asthma sourcebook. 2nd ed. Omnigraphics, Detroit, MI. 
Currie, B.A. and B. Bass. 2008. Estimates of air pollution mitigation with green plants and green roofs using the UFORE model. Urban Ecosyst. 11:409-422.

Devlin, R.B., L.A. Dailey, J. Carter, L. Cazares, W. Setzer, and D.B. Peden. 1996. The effect of ozone on house dust mite allergen-induced nasal inflammation in asthmatics, p. 151-170. In: R.B. Gammage and B.A. Berven (eds.). Indoor air and human health. 2nd ed. CRC, Boca Raton, FL.

Diamond, D.D., D.H. Riskind, and S.L. Orzell. 1987. A framework for plant community classification and conservation in Texas. Tex. J. Sci. 39:203-221.

Dockery, D. and A. Pope. 1996. Epidemiology of acute health effects: Summary of time-series studies, p. 123-148. In: R. Wilson and J. Spengler (eds.). Particles in our air: Concentrations and health effects. Harvard Univ. Press, Cambridge, MA.

Edelman, N.H. 1997. Family guide to asthma and allergies: How you and your children can breathe easier. Little Brown, New York.

Elsom, D. 1996. Smog alert: Managing urban air quality. Earthscan, London.

Labor Market and Career Information Department of the Texas Workforce Comission. 2006. Metropolitan Statistical Area and Composite Counties: State of Texas. 17 Jan. 2012. <http://www.tracer2. $\mathrm{com} /$ default.asp?PAGEID $=149>$.

Lara, M., W. Nicholas, S. Moron, M.E. Vaiana, B. Genovese, and G. Rachelefsky. 2001. Improving childhood asthma outcomes in the United States: A blueprint for policy and action. Rand, Santa Monica, CA.

Lovasi, G.S., J.W. Quinn, K.M. Neckerman, M.S. Perzanowski, and A. Rundle. 2008. Children living in areas with more street trees have lower prevalence of asthma. J. Epidemiol. Community Health 62: 647-649.

MacNaughton, K. 2007. Pollen: A Potent Seasonal Allergen and Asthma Trigger. 6 May 2010. <http://asthma.about. $\mathrm{com} / \mathrm{od} /$ asthmatriggers/qt/pollentrigger.htm>.
Matzka, J. and B.A. Maher. 1999. Magnetic biomonitoring of roadside tree leaves: Identification of spatial and temporal variations in vehicular-derived particulates. Atmos. Environ. 33:4565-4569.

National Asthma Education and Prevention Program. 2007. Guidelines for the Diagnosis and Management of Asthma. 10 Feb. 2012. <http://www.nhlbi.nih. gov/guidelines/asthma/asthgdln.htm>.

Neidell, M.J. 2004. Air pollution, health, and socioeconomic status: The effect of outdoor air quality on childhood asthma. J. Health Econ. 23:1209-1236.

O'Connell, E.J. 2004. The burden of atopy and asthma in children. Allergy 59(S78):7-11.

Pénard-Morand, C., C. Raherison, D. Charpin, C. Kopferschmitt, F. Lavaud, D. Caillaud, and I. Annesi-Maesano. 2010. Long-term exposure to closeproximity air pollution and asthma and allergies in urban children. Eur. Respir. J. $36: 33-40$

Petit, J., D.L. Bassert, and C. Kollin. 1998. Building greener neighborhoods: Trees as part of the plan. 2nd ed. Amer. Forests, Natl. Assn. Home Builders, Washington, DC.

Rao, P.S., A.G. Gavane, S.S. Ankam, M.F Ansari, V.I. Pandit, and P. Nema. 2004. Performance evaluation of a green belt in a petroleum refinery: A case study. Ecol. Eng. 23:77-84.

Sieghardt, M., E. Mursch-Radlgruber, E. Paoletti, E. Couenberg, A. Dimitrakopoulus, F. Rego, A. Hatzistathis, and T.B. Randrup. 2005. The abiotic urban environment: Impact of urban growing conditions on urban vegetation, p. 281-323. In: C.C. Konijnendijk, N. Kjell, T.B. Randrup, and J. Schipperijn (eds.). Urban forests and trees. Springer-Verlag, Berlin/Heidelberg, Germany.

Smith, D.H., D.C. Malone, K.A. Lawson, L.J. Okamoto, C. Battista, and W.B. Saunders. 1997. A national estimate of the economic costs of asthma. Amer. J. Respir. Crit. Care Med. 156:787-793.
Sommers, M.S., S.A. Johnson, and T.A. Beery. 2007. Diseases and disorders: A nursing therapeutics manual. 3rd ed. F.A. Davis, Philadelphia, PA.

Texas Commission on Environmental Quality. 2012. Monthly summary report. 18 Jan. 2012. <http://www.tceq.texas. gov/cgi-bin/compliance/monops/ monthly_summary.pl>.

Thurston, G.D. and K. Ito. 1999. Epidemiological studies of ozone exposure effects, p. 485-510. In: S.T. Holgate, J.M. Samet, H.S. Koren, and R.L. Maynard (eds.). Air pollution and health. Academic Press, San Diego, CA.

Tunnicliffe, W.S. and J.G. Ayres. 2001. Trends in air pollution related disease, $\mathrm{p}$. 21-84. In: P. Brimblecombe and R.L. Maynard (eds.). The urban atmosphere and its effects. Imperial College Press, London.

U.S. Department of the Interior. 2010 . Landsat $5^{\mathrm{TM}}$ imagery. 2 Feb. 2010. $<$ http://glovis.usgs.gov/>.

U.S. Department of the Interior. 2012. Multi-Resolution Land Characteristics National Land Cover Database. 16 May 2012. <http://www.mrlc.gov/>

Walling, A.D. 2002. Does air pollution affect childhood asthma? Amer. Fam. Physician 65:1685.

Williams, A.L. 2005. Poor air quality threatens human health, p. 20-24. In: A.C. Nakaya (ed.). Is air pollution a serious threat to health? Greenhaven Press, Farmington Hills, MI

Wilson VanVoorhis, C.R. and B.L. Morgan. 2007. Understanding power and rules of thumb for determining sample size. Tutorials Quantitative Methods Psychol. $3: 43-50$.

Woodruff, T.J., D.A. Axelrad, A.D. Kyle, O. Nweke, and G.G. Miller. 2003. America's Children and the Environment: Measurement of Contaminants, Body Burdens, and Illnesses. 2nd ed. 17 Jan. 2012. <http:// www.epa.gov/ace/publications / ace_2003.pdf>. 